\title{
The Organization of the Lexicon
}

\section{The Polysemy of Grow and Disambiguation}

\author{
Yukiko Sasaki Alam \\ Dept. of Digital Media Science \\ Hosei University \\ Tokyo, Japan \\ sasaki@k.hosei.ac.jp
}

\begin{abstract}
This paper demonstrates that the polysemy of the verb grow is a result of natural extension of individual meanings connoted by its basic literal meaning and that the polysemy of grow, as such, can be disambiguated by applying simple rules of elimination to the argument structures, which are the contexts that make particular senses viable.
\end{abstract}

\section{Introduction $^{1}$}

This paper claims that the polysemy of the verb grow is a result of natural extension of meanings connoted by the basic literal meaning and that the connotations develop into each independent meaning of grow by requiring different semantic features of the arguments. The connotations of the literal meaning of grow become viable in a new context of argument structure.

It will be demonstrated that for the computational treatment of disambiguation, it is not necessary to exhaust all the features involved in a particular meaning of grow, but the application of simple rules of elimination to the argument structure would be sufficient.

\footnotetext{
${ }^{1}$ I would like to thank Alan Wallington, John Barnde, Mark Lee and Sheila Glasbey for organizing the workshop entitled The Lexicon and Figurative Language at ACL 2003 in Sapporo, Japan on July 11, 2003. My thanks also go to three anonymous reviewers for valuable comments. I alone, however, am responsible for any errors this paper may contain.
}

The second section will discuss each sense of grow, focusing on the semantic components of the arguments, and on the relationships among them. I will demonstrate what is required to disambiguate the polysemy of grow in the third section, which is followed by short sections for implications and conclusion.

\section{Relationships of extended meanings}

Viewed by using such thematic roles of verbs as GOAL and SOURCE, the meanings of the verb grow shows an interesting relationship among each other. According to the etymology of the word, the original sense would be for a plant to germinate and develop or for a living thing to undergo natural development, for instance, by increasing in size and changing physically. The meanings of grow could be illustrated as below ${ }^{2}$ :

(1) grow_proto

a. It's too cold for orchids to grow here.

b. Crocuses don't grow in ponds.

c. Later, forests grew on the delta.

\footnotetext{
${ }^{2}$ The following idiomatic uses of grow are not included in the discussion of this paper:

(i) His new jacket's a bit big for him now, but he'll soon grow into it.

(ii) I didn't like blue cheese at first, but the taste has kind of grown on me.

(iii) Jonathan still sucks his thumb, but we hope he'll grow out of it.

(iv) What will you be when you grow up?
} 
d. A dozen or so bushes grew from a wide fissure.

e. He grew mentally and spiritually. ${ }^{3}$

(2) grow_appear

a. A small glimmer of happiness grew on their faces.

b. Confidence grew in him.

c. Their love grew out of friendship.

d. The book grew out of their weekly meetings.

e. In those days such interests rarely grew from the pupils' enthusiasm or choice.

(3) grow_increase

a. His confidence grew.

b. He grew in confidence.

c. The city's population grew from 130,000 to more than 500,000.

d. The ethnic minorities grew in influence.

e. The European market for ISDN telephone lines will grow in value from $£ 200,000$ now to $£ 2.5 \mathrm{~m}$ by the year 2000 .

(4) grow_change
a. A boy grows to manhood.
b. A boy grows into a man.
c. His love grew cold
d. I am growing to hate him.
e. They grew from girl to woman.
f. The city of London grew from a small fish- ing village to a great city.

(5) grow_caused
a. The farmer grew corn in this field last year.
b. He's growing a beard.
c. Plants grow roots.
d. Cattle often grow horns.

\section{A. grow_proto and grow_appear}

The meaning of 'grow_proto' connotes a combination of appearance, development, increase in size and change, all of which seem to have developed to be independent meanings of grow through the

\footnotetext{
${ }^{3}$ He grew mentally and spiritually in (1e) may be a result of
} personification. metaphorical process. Therefore, each developed meaning has the undertone of the basic meaning of grow.

The characteristic properties of the meaning of 'grow_proto' are that the SUBJECT noun phrase refers to a living thing such as a plant and a human and that it may take a component that plays a role of denoting place for both growing and existence. Such a component is called LOCUS among such scholars who study the semantic structure of verbs as Gruber (1965), Starosta (1978) and Ostler $(1980)^{4}$.

Unlike the meaning of 'grow_proto', the meaning of 'grow_appear' takes the SUBJECT noun phrase that does not refer to a living thing. Therefore, the meanings of 'grow_proto' and 'grow_appear' are complementary in terms of the features of the SUBJECT noun phrases. In addition, unlike the reading of 'grow_proto', the reading of 'grow_appear' does not necessarily require a LOCUS component having the feature of PLACE, but the feature of denoting a physical object such as a face in (2a) would be sufficient. Thus, it could be stated that the reading of 'grow_appear' has less semantic constraint on the LOCUS component than that of 'grow_proto'.

In addition, the reading of 'grow_appear' takes a component indicating source of coming into existence, which can be called SOURCE because of the role of indicating the source of action. The SOURCE element refers to an abstract entity as in (2c) through (2e). Difference in the semantic features of the components in the readings of 'grow_proto' and 'grow_appear' is illustrated in the following table:

\footnotetext{
${ }^{4}$ It should be noted that LOCUS should be distinguished from LOCATION, which indicates place where AGENT takes action. Take the following for instance:

a. He is writing a letter on a letter pad.

b. He is writing a letter in the kitchen.

The phrase on a letter pad functions as LOCUS whereas in the kitchen, LOCATION.
} 
(6)

a. grow_proto

SUBJECT + GROW (+ LOCUS or SOURCE) ${ }^{5}$

b. grow_appear

SUBJECT + GROW + LOCUS or SOURCE

\begin{tabular}{|l|l|l|l|}
\hline readings & $\begin{array}{l}\text { semantics } \\
\text { of } \\
\text { SUBJECT }\end{array}$ & $\begin{array}{l}\text { semantics } \\
\text { of } \\
\text { LOCUS }\end{array}$ & $\begin{array}{l}\text { semantics } \\
\text { of } \\
\text { SOURCE }\end{array}$ \\
\hline grow_proto & $\begin{array}{l}\text { living } \\
\text { thing }\end{array}$ & place & place \\
\hline grow_appear & $\begin{array}{l}\text { non-living } \\
\text { thing }\end{array}$ & $\begin{array}{l}\text { physical } \\
\text { entity }\end{array}$ & $\begin{array}{l}\text { abstract } \\
\text { entity }\end{array}$ \\
\hline
\end{tabular}

Although both readings take the construction in the form of SUBJECT + GROW + LOCUS, the reading of 'grow_appear' needs either the LOCUS or the SOURCE whereas the reading of 'grow_proto' can have the SUBJECT only.

\section{B. grow_increase}

The SUBJECT noun phrase of the reading of 'grow_increase' refers either to a physical object or to an abstract object. This reading permits an interesting interchange of two constructions, as illustrated below:

(7)

a. His confidence grew. (= 3a) (POSSESSOR's ATTRIBUTE GROW)

b. He grew in confidence. $(=3 b)$ (POSSESSOR GROW in ATTRIBUTE)

As (7b) shows, the POSSESSOR component can be the SUBJECT of the sentence, and the ATTRIBUTE can appear in the form of in + ATTRIBUTE. Let us look into the phrase in confidence in (7b). In fact, we find the third construction somewhat similar in meaning to those in (7a) and (7b), which is repeated below:

(8) Confidence grew in him. $(=2 b)$

Let us use the following conceptual diagrams for our exploration of the nature of the phrase "in + ATTRIBUTE":

\footnotetext{
${ }^{5}$ Parentheses indicate the item inside is optional.
}

(9)
a. A flower grew in the pot.
b. Confidence grew in him. $(=2 b, 8)$
c. He grew in confidence. $(=3 \mathrm{~b}, 7 \mathrm{~b})$
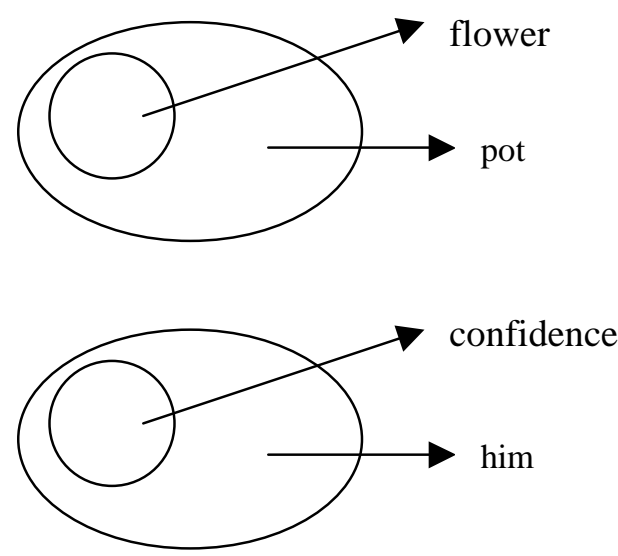

The two diagrams suggest that in (9a) the part, $a$ flower, is the SUBJECT of the sentence, and the whole, the pot, is the LOCUS. Likewise, in (9b) the part, confidence, is the SUBJECT while the whole, him, is the LOCUS. Alternatively, by using Talmy's (1978) terminology in cognitive psychology, we could call the part 'figure' and the whole 'ground'. Moreover, Brugman and Lakoff (1988) treated the figure as an element in focus and the ground as an element not in focus in the paper dealing with prepositions. Drawing on the insight of previous researchers, I call the thematic role of the phrase in confidence FOCUS. The FOCUS element in this construction always appears in the form of in + FOCUS noun, and the noun refers to an abstract entity.

Furthermore, the reading of 'grow_increase' may appear with phrases indicating a finishing point of increase as well as a starting point. As those phrases are preceded by the prepositions to and from, I call their thematic roles GOAL and SOURCE respectively according to the naming convention of thematic roles. As the examples in (3c) and (3e) show, the GOAL and SOURCE elements denote quantities. It should also be noted that the reading of 'grow_increase' does not take the SOURCE element alone without accompanying the GOAL element. Where there is a SOURCE element, so is there a GOAL element. 
Thus, we need three-fold constructions in this reading, as illustrated below;

(10) grow_increase

\section{(a) SUBJECT+ GROW}

\begin{tabular}{|l|l|l|l|}
\hline $\begin{array}{l}\text { (a) semantics } \\
\text { of SUBJECT } \\
\text { (possessor's } \\
\text { attribute) }\end{array}$ & FOCUS & $\begin{array}{l}\text { GOAL } \\
\text { (finishing } \\
\text { point) }\end{array}$ & $\begin{array}{l}\text { SOURCE } \\
\text { (starting } \\
\text { point) }\end{array}$ \\
\hline abstract entity & (None) & (None) & (None) \\
\hline
\end{tabular}

(b) SUBJECT + GROW + in + FOCUS

\begin{tabular}{|l|l|l|l|}
\hline $\begin{array}{l}\text { (b) semantics } \\
\text { of SUBJECT } \\
\text { (possessor) }\end{array}$ & $\begin{array}{l}\text { FOCUS } \\
\text { (attribute) }\end{array}$ & $\begin{array}{l}\text { GOAL } \\
\text { (finishing } \\
\text { point) }\end{array}$ & $\begin{array}{l}\text { SOURCE } \\
\text { (starting } \\
\text { point) }\end{array}$ \\
\hline $\begin{array}{l}\text { abstract or } \\
\text { physical en- } \\
\text { tity }\end{array}$ & $\begin{array}{l}\text { abstract } \\
\text { entity }\end{array}$ & (None) & (None) \\
\hline
\end{tabular}

(c) SUBJECT + GROW $(+$ in + FOCUS $)+$ GOAL $(+ \text { SOURCE })^{6}$

\begin{tabular}{|l|l|l|l|}
\hline $\begin{array}{l}\text { (c) semantics } \\
\text { of SUBJECT }\end{array}$ & $\begin{array}{l}\text { FOCUS } \\
\text { (attribute) }\end{array}$ & $\begin{array}{l}\text { GOAL } \\
\text { (finishing } \\
\text { point) }\end{array}$ & $\begin{array}{l}\text { SOURCE } \\
\text { (starting } \\
\text { point) }\end{array}$ \\
\hline $\begin{array}{l}\text { abstract or } \\
\text { physical en- } \\
\text { tity }\end{array}$ & $\begin{array}{l}\text { abstract } \\
\text { entity }\end{array}$ & quantity & quantity \\
\hline
\end{tabular}

\section{C. grow_change}

The reading of 'grow_change' seems to derive by focusing the aspect of change or development connoted by the basic meaning of grow. The SUBJECT noun phrase refers to an entity that undergoes change of state. The minimum requirement of this reading is an element that indicates the final state of change whether the final state is expressed as a prepositional phrase as in to manhood (4a) and into a man (4b), as an adjective as in grew cold (4c), or as an infinitival phrase as in growing to hate him (4d). This reading may optionally appear with an element denoting the initial state of change, as in from girl to woman in $(4 \mathrm{e})$.

\footnotetext{
${ }^{6}$ Parentheses indicate the item inside is optional.
}

The characteristics of this reading is that the semantic features in the SUBJECT, GOAL and, if any, SOURCE elements should agree in feature specification. For instance, in (4b) the semantic features of boy and man should agree in feature specification for well-formedness. It is easy to detect some cases of this reading syntactically. Only this reading permits such a construction as His love grew cold in (4c) and I am growing to hate him in (4d). The following table shows semantic features for the reading of 'grow_change' in constructions other than (4c) and (4d), both of which require a special syntactic treatment.

(11) grow_change (requiring the feature agreement among the three roles)

\begin{tabular}{|l|lr|l|}
\hline $\begin{array}{l}\text { semantics of } \\
\text { SUBJECT }\end{array}$ & $\begin{array}{l}\text { semantics of } \\
\text { GOAL } \\
\text { quired } \\
\text { ment) }\end{array}$ & $\begin{array}{l}\text { semantics of } \\
\text { ele- }\end{array}$ & $\begin{array}{l}\text { SOURCE (op- } \\
\text { tional element) }\end{array}$ \\
\hline physical entity & physical entity & physical entity \\
\hline abstract entity & abstract entity & abstract entity \\
\hline
\end{tabular}

\section{D. grow_caused}

The reading of 'grow_caused' differs structurally from the other readings discussed above in that it requires the component which plays the grammatical role of OBJECT. In other words, grow in this reading is a transitive verb. This reading is derived from the reading of 'grow_proto' by adding the AGENT element, and thus it may take the LOCUS element, as in grew corn in this field (5a). Thus it is not difficult to distinguish this reading from the other readings.

To sum up, a combination of connotations of the literal meaning of 'grow_proto' each seems to become a focus and develop into an independent meaning of grow. The shift of focus has caused the change of the semantics of the argument, resulting in a different argument structure from that for the basic meanig: for instance, the meaning of increase does not take the LOCUS that denotes place any longer, but can instead have a FOCUS element that denotes an abstract entity. Likewise, the GOAL and SOURCE elements in the reading of 'grow_increase' do not denote place, but indicate a finishing and a starting points of increase respectively. The reading of 'grow_change' may have 
GOAL and SOURCE elements, but what they really represent is the final and initial states of change. Yet, the readings of 'grow_increase' and 'grow_change' are related to each other, and share something in common: both events are realized by growing. All extended meanings carry the undertone of the basic meaning with them. These meanings seem to be developed from 'grow_proto' as if cell division takes place. This kind of lexical organization and extension would reduce memory load on the learner.

\section{For computational treatment}

Finally, I would like to make comments on the computational treatment of the polysemy of grow. The following table gives an idea of which readings are similar syntactically and semantically and of what is required to disambiguate the polysemy. For the computational treatment of disambiguation, we would not need to exhaust all the features involved in argument structure for each meaning of a verb, but to have sufficient rules of elimination of other readings would suffice.

Following is a table showing relationships among the meanings of grow, which is organized in terms of grammatical and thematic roles. ${ }^{7}$

\begin{tabular}{|l|l|l|l|l|l|}
\hline Meanings & $\begin{array}{l}\text { Just } \\
\text { SUBJ }\end{array}$ & L & G & G\&S & S \\
\hline grow_proto & ok & ok & & & ok \\
\hline grow_appear & & ok & & & ok \\
\hline grow_increase & ok & $\begin{array}{l}\text { ok } \\
(=F)\end{array}$ & ok & ok & \\
\hline grow_change & & & ok & ok & \\
\hline
\end{tabular}

$\mathrm{L}=\mathrm{LOCUS}, \mathrm{F}=\mathrm{FOCUS}, \mathrm{G}=\mathrm{GOAL}, \mathrm{G} \& \mathrm{~S}=\mathrm{GOAL}$ $\&$ SOURCE, $S=$ SOURCE

\footnotetext{
${ }^{7}$ I will not include the reading of 'grow_caused' because it has a distintive construction by having the OBJECT, and is easy to distinguish from the others. In addition, constructions such as His love grew cold and I am growing to hate him are not included in this table because these are typical of the rea ding of 'grow_change', and are easy to detect syntactically.

8 " $=F "$ means that in this reading the LOCUS element has a more specific role, FOCUS.
}

The construction in the form of SUBJECT + GROW appears in both readings of 'grow_proto' and 'grow_increase'. Both readings are distinguishable from each other by the semantics of the SUBJECT noun phrases. The SUBJECT noun phrase in the reading of 'grow_proto' requires an entity referring to a living thing, while that in the reading of 'grow_increase', an abstract entity.

Three readings, 'grow_proto', 'grow_appear' and 'grow_increase' take the form of SUBJECT noun phrase + GROW + $\mathrm{P}^{9}+$ LOCUS noun phrase; in particular the last reading in the form of SUBJECT + GROW + in + FOCUS noun instead. As the LOCUS in the reading of 'grow_proto' denotes the PLACE feature and the others do not, the reading of 'grow_proto' can be distinguished from the other two. Between the remaining two, the reading of 'grow_appear' takes the LOCUS requiring a physical entity whereas the reading of 'grow_increase', an abstract entity.

The readings of 'grow_incease' and 'grow_change' may appear in the form of SUBJECT + GROW + to + GOAL or in the form of SUBJECT + GROW + from + SOURCE + to + GOAL. They are distinguishable because the GOAL and SOURCE in the reading of 'grow_increase' include features of QUANTITY while those in the reading of 'grow_change' do not.

The readings of 'grow_proto' and 'grow_appear' take the form of SUBJECT + GROW + from + SOURCE, but while the SOURCE in the reading of 'grow_appear' refers to an abstract entity, that in the reading of 'grow_proto' does not. As mentioned above, the two readings are also distinguishable in terms of the semantic features of the SUBJECT noun phrases because the SUBJECT of the reading of 'grow_proto' requires a feature indicating a living thing while that of the reading of 'grow_appear' should not.

As discussed above, once rules of elimination are prepared, it would not be difficult to disambiguate the polysemy of a word, because the polysemy is based on the extension of meanings that do not overlap and the contexts that make the extensions

\footnotetext{
9 "P" stands for preposition.
} 
viable should not overlap either. The contexts in the case of verbs are the argument structures.

\section{Implications}

Interestingly, the hypothesis of the relationship between the primary sense and other extended senses in this study differs from that in Tyler and Evans' (2001) study on the polysemy of the preposition over. This study claims that the basic or primary sense of grow has a combination of individual connotations such as change of state, increase and appearance, and that grow acquires a new sense extended from each individual connotation by allowing a different argument structure. On the other hand, the primary sense of over proposed in Tyler and Evans 'represents a highly idealized abstraction from our rich recurring experience of spatial scenes' and 'other distinct senses instantiated in the polysemy network for over result from pragmatic strengthening, i.e. reanalysis and encoding.' (p. 762) It would be an open question whether this difference is due to different subject matters, i.e. between the verb and the preposition, or due to different approaches, i.e. between computationally motivated and psycholinguistic approaches.

However, both studies have a common underlying thesis that the lexicon is highly motivated exhibiting regularities. This is in contrast to the view generally held by Minimalist linguists that the lexicon is not organized by general principles (Chomsky 1995). ${ }^{10}$

The advantage of the analysis of the polysemy of grow proposed in this study is that it is somewhat similar to analyses we find in the entries for grow in dictionaries. This suggests that it might be possible to use analyses of lexical entries listed in traditional dictionaries for computational purposes.

\section{Conclusion}

This paper has discussed the relationships of the polysemy of the verb grow by examining the se-

\footnotetext{
${ }^{10}$ The study of the lexicon and in particular the semantic polysemy has never been a subject of serious linguistic research in the framework of Generative Linguistics. As the study of the lexicon has been scarce and the research has to cover a vast realm of linguistic data and activities, this field is in dire need of future research.
}

mantic features of the arguments. It has demonstrated that a combination of meanings connoted in the basic literal meaning each develops into an independent meaning of grow, attaining a new context that makes the meanig effective. The polysemy of grow is a natural extension of connotations of its basic meaning. This type of lexical organization, if this assumption is in the right direction, would have reduced memory load on the learner. It has also pointed out that for the computational treatment of disambiguation, it is not necessary to exhaust all the features involved in a particular reading of the polysemy, but that simple rules of elimination of other readings should suffice. This claim has been demonstrated by disambiguating the polysemy of grow by applying the rules of elimination to the argument structures, which are in fact the contexts that make particular meanings viable.

\section{References}

Abraham, Werner. (ed.) 1978. Valence, semantic case and grammatical relations. Amsterdam: Benjamins.

Brugman, Claudia and George Lakoff. 1988. Cognitive topology and lexical networks. Lexical ambiguity resolution, ed. by Steven Small, Garrison Cottrell, and Michael Tanenhaus, 477-507. Palo Alto, CA: Morgan Kaufman.

Chomsky, Noam. 1995. Categories and transformations. The minimalist program, by Noam Chomsky, 219394. Cambridge, MA: MIT Press.

Gruber, Jeffrey. 1965. Studies in lexical relations. Cambridge, Mass.: MIT dissertation.

Ostler, Nicholas. 1980. A theory of case linking and agreement. Bloomington: Indiana University Linguistic Club.

Starosta, Stanly. 1978. The one per cent solution. In Abraham, 459-576.

Talmy, Leonard. 1978. Figure and ground in complex sentences. Universals in human language, vol. 4, ed. by Joseph Greenberg, 625-649. Stanford, CA: Stanford University Press.

Tyler, Andrea and Vyvyan Evans. 2001. Reconsidering prepositional polysemy networks: The case of over. Language 77.724-765. 